\title{
Ectopic ovarian pregnancy after intracytoplasmic sperm injection with testicular spermatozoa - a case report
}

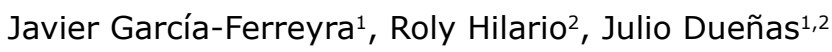 \\ ${ }^{1}$ FERTILAB Assisted Reproduction Laboratories, Lima, Peru \\ 2PROCREAR Fertility Center, Lima, Peru
}

\begin{abstract}
Ovarian ectopic pregnancy is a rare event in both natural and assisted human reproduction settings. There are few reports of this event after in vitro fertilization. Diagnosis can be challenging, since it requires specific medical expertise. Patients with this condition call for careful management during treatment so as to not affect their fertility potential. This paper describes the case of a woman submitted to ICSI and embryo transfer who subsequently had an ovarian ectopic pregnancy and underwent a laparoscopic partial right oophorectomy
\end{abstract}

Keywords: ectopic pregnancy, ovarian pregnancy, ART

\section{INTRODUCTION}

Assisted reproduction technologies (ART) have helped infertile couples achieve satisfactory implantation and pregnancy rates. Nevertheless, ART procedures have their inherent risks, one of which is ectopic pregnancy (EP). In cases of ectopic pregnancy, the blastocyst implants outside the uterine cavity. The incidence of EP ranges between $1.2-1.4 \%$ for spontaneous pregnancies (Rana et al., 2013 ), and from $1.5 \%$ to $2.1 \%$ in patients undergoing IVF/ICSI (Londra et al., 2015). Approximately $98 \%$ of EP cases occur in the fallopian tubes, one percent in the abdominal region (Atrash et al., 1987), and, in extremely rare occasions, in the ovaries, with an incidence of $0.5-3 \%$ (Raziel et al., 2004). An ectopic pregnancy involves direct fertilization of an unreleased mature egg inside an ovary, or retrograde migration of the embryo into an ovary via the fallopian tube. Normally, during embryo transfer (ET), the embryos are placed $1.5-2.0 \mathrm{~cm}$ from the uterine fundus. Ovarian pregnancy is thought to occur due to a retrograde migration of an embryo via the tube and the implantation of such embryo in the ovary. This report describes a case of ovarian pregnancy after ICSI with testicular spermatozoa and fresh embryo transfer.

\section{CASE REPORT}

A 25-year-old female and her 57-year-old male partner came to our fertility center on September 2016 for an ICSI procedure with cryopreserved testicular spermatozoa. The patient had regular menstrual cycles, and normal uterus, tubes and ovaries. FSH, LH and estradiol levels at day 3 were $5.25 \mathrm{IU}, 5.67 \mathrm{IU}$, and $30.08 \mathrm{pmol} / \mathrm{l}$, respectively. The ovarian cycle was stimulated using gonadotropins according to previously established stimulation protocols (Tavmergen et al., 2002). Starting on day 2, the patient received a daily dose of $187.5 \mathrm{IU}$ of $\mathrm{rFSH}$ (Gonal ${ }^{\circledR}$, Merck Serono Laboratories, Peru) until day 11, when ovulation was triggered by $250 \mu \mathrm{g}$ of recombinant human chorionic gonadotropin (Ovidrel ${ }^{\circledR}$, Merck Sereno Laboratories, Peru). A total of 10 oocytes were collected, and nine were injected with testicular sperm from her partner, leading to the development of four blastocysts on day 5. Two blastocysts were transferred and the remaining ones were frozen. Micronized Progesterone $(600 \mathrm{mg} / \mathrm{day}$, vaginally; Geslutin ${ }^{\circledR}$, Tecnofarma, Peru) was used for luteal support. Two weeks later, tests showed a BhCG level of $44.69 \mathrm{mIU} /$ $\mathrm{ml}$; eight days later, the patient's BhCG level had increased to $9963 \mathrm{mIU} / \mathrm{ml}$. At seven weeks, the patient reported moderate abdominal pain. Transvaginal ultrasound examination did not find intrauterine pregnancy, but a paraovarian mass in her right ovary. The patient was hospitalized and underwent laparoscopic examination, and was diagnosed with right ovarian ectopic pregnancy. Blood and tissue were removed from the pelvic area and a partial right oophorectomy was performed. Histopathology confirmed the diagnosis of ovarian pregnancy with one sac. The patient recovered well from surgery.

\section{DISCUSSION}

It has been estimated that $10 \%$ of the women hospitalized for ectopic pregnancy in the developing world die (Leke et al., 2004). Several authors have reported that ART procedures increase ectopic pregnancy rates (Marcus \& Brinsden, 1995; Strandell et al., 1999; Clayton et al., 2006), and associations have been described between in vitro fertilization (IVF) and a $2-5 \%$ risk of EP, which may increase in the presence of tubal disease (Clayton et al., 2006). According to Marcus \& Brinsden (1995), 4.5-6\% of all cases of extrauterine pregnancy and $0.35 \%$ of all clinical pregnancies are ovarian pregnancies. Choi et al. (2011) looked into 3081 cases of ectopic pregnancy and found that 49 were cases of ovarian pregnancy $(1.59 \%)$, as similarly reported by Grimes et al. (1983); Gaudoin et al. (1996) and Raziel et al. (2004).

Retrograde migration of the blastocyst into the fallopian tube and implantation in an ovary may be one of the causes of ovarian EP. Ovarian pregnancy is diagnosed based on four criteria: (1) the fallopian tubes and the fimbriae must be intact and separated from the ovary; (2) the pregnancy must occupy the normal position in the ovary; (3) the ovary must be attached to the uterus through the uteroovarian ligament; and (4) there must be ovarian tissue attached to the pregnancy in the specimen (Spiegelberg, 1878). However, diagnosis is difficult and relies on the suspicion and judgment of experienced physicians, since this rare condition is often asymptomatic until the ovaries are ruptured.

Possible risk factors to ovarian ectopic pregnancy include use of intrauterine devices, history of laparotomy or laparoscopic surgery, endometriosis, ART procedures, and uterine anomalies. In our report, the patient was healthy and had no history of surgery or infectious/inflammatory process. Oophorectomy or salpingo-oophorectomy is the traditional treatment for ovarian ectopic pregnancy. However, a wedge resection or the partial removal of the gestational product alone is the ideal treatment to maintain 
fertility, as shown in this study. Finally, diagnosis of EP is of the utmost importance, as it may lead to proper surgical treatment to safeguard and preserve fertility.

\section{CONFLICT OF INTEREST}

The authors have no conflicts of interest to report.

\section{Corresponding author:}

Javier García-Ferreyra

FERTILAB Laboratory of Assisted Reproduction Lima - Peru

E-mail: jgarciaf@fertilab.pe

\section{REFERENCES}

Atrash HK, Friede A, Hogue CJ. Abdominal pregnancy in the United States: frequency and maternal mortality. Obstet Gynecol. 1987;69:333-7. PMID: 3822281

Choi HJ, Im KS, Jung HJ, Lim KT, Mok JE, Kwon YS. Clinical analysis of ovarian pregnancy: a report of 49 cases. Eur J Obst Gynecol Reprod Biol. 2011;158:87-9. PMID: 21601978 DOI: 10.1016/j.ejogrb.2011.04.015

Clayton HB, Schieve LA, Peterson HB, Jamieson DJ, Reynolds MA, Wright VC. Ectopic pregnancy risk with assisted reproductive technology procedures. Obstet Gynecol. 2006;107:595-604. PMID: 16507930 DOI: 10.1097/01.AOG.0000196503.78126.62

Gaudoin MR, Coulter $K L$, Robins $A M$, Verghese $A$, Hanretty KP. Is the incidence of ovarian ectopic pregnancy increasing? Eur J Obstet Gynecol Reprod Biol. 1996;70:141-3. PMID: 9119093 DOI: http://dx.doi.org/10.1016/S0301-2115(95)02557-X

Grimes HG, Nosal RA, Gallagher JC. Ovarian pregnancy: a series of 24 cases. Obstet Gynecol. 1983;61:174-80. PMID: 6823359
Leke RJ, Goyaux N, Matsuda T, Thonneau PF. Ectopic pregnancy in Africa: a population-based study. Obstet Gynecol. 2004;103:692-7. PMID: 15051561 DOI: 10.1097/01.AOG.0000120146.48098.f2

Londra L, Moreau C, Strobino D, Garcia J, Zacur H, Zhao Y. Ectopic pregnancy after in vitro fertilization: differences between fresh and frozen-thawed cycles. Fertil Steril. 2015;104:110-8. PMID: 25956363 DOI: $10.1016 /$ j.fertnstert.2015.04.009

Marcus SF, Brinsden PR. Analysis of the incidence and risk factors associated with ectopic pregnancy following in-vitro fertilization and embryo transfer. Hum Reprod. 1995;10:199-203. PMID: 7745054 DOI: http://dx.doi.org/10.1093/humrep/10.1.199

Rana P, Kazmi I, Singh R, Afzal M, Al-Abbasi FA, Aseeri A, Singh R, Khan R, Anwar F. Ectopic pregnancy: a review. Arch Gynecol Obstet. 2013;288:747-57. PMID: 23793551 DOI: $10.1007 / \mathrm{s} 00404-013-2929-2$

Raziel A, Schachter M, Mordechai E, Friedler S, Panski M, Ron-El R. Ovarian pregnancy-a 12-year experience of 19 cases in one institution. Eur J Obstet Gynecol Reprod Biol. 2004;114:92-6. PMID: 15099878 DOI: $10.1016 /$ j.ejogrb.2003.09.038

Spiegelberg O. Casuistry in ovarian pregnancy. Arch Gynecol Surv. 1878;13:73-9.

Strandell A, Thorburn J, Hamberger L. Risk factors for ectopic pregnancy in assisted reproduction. Fertil Steril. 1999;71:282-6. PMID: 9988399 DOI: http://dx.doi.org/10.1016/S0015-0282(98)00441-5

Tavmergen E, Göker EN, Sendag F, Sendag H, Levi R. Comparison of short and long ovulation induction protocols used in ART application according to the ovarian response and outcome of pregnancy. Arch Gynecol Obstet. 2002;266:5-11. PMID: 11998967 DOI: http://dx.doi.org/10.1007/PL00007494 